\title{
Did the universe design itself?
}

\section{Philip Goff ${ }^{1}$}

Received: 30 October 2018 / Accepted: 8 November 2018 / Published online: 24 November 2018

(c) The Author(s) 2018

\begin{abstract}
Many philosophers and scientists believe that we need an explanation as to why the laws of physics and the initial conditions of the universe are fine-tuned for life. The standard two options are: theism and the multiverse hypothesis. Both of these theories are extravagant and arguably have false predictions. Drawing on contemporary philosophy of mind, I outline a form of panpsychism that I believe offers a more parsimonious and less problematic explanation of cosmological fine-tuning.
\end{abstract}

Keywords Fine-tuning · Multiverse $\cdot$ Panpsychism $\cdot$ Russellian monism · Theism · Problem of evil $\cdot$ Design arguments

Once ridiculed, panpsychism is increasingly being taken seriously in contemporary analytic philosophy of mind. Many hope that it can provide an attractive middle way between physicalism and dualism, avoiding the deep difficulties associated with each. In this paper, I will explore another potential application of panpsychism: explaining cosmic fine-tuning. There are a number of parameters in the basic laws of physics and initial conditions of the universe that are such that, for life to be possible, the values of those parameters needed to fall in an exceedingly narrow range. Many scientists and philosophers think there must be an explanation of why, of all the values they might have had, these parameters have precisely the values needed in order for life to be possible. There are deep difficulties with both of the standard explanations of this 'fine-tuning' of the laws of nature: theism and the multiverse hypothesis. I will argue that if one adopts a certain form of panpsychism, one can explain the fine-tuning in terms of the mental capacities of the universe, and that this constitutes a significantly less problematic and significantly more parsimonious explanation of the fine-tuning.

Philip Goff

philip.a.goff@durham.ac.uk

1 Durham University, Durham, UK 


\section{I-Russellian panpsychism}

\section{Russellian monism}

To understand recent sympathies for panpsychism, we must begin with the view that has become known as 'Russellian monism', so-called because it is inspired by certain theses defended by Russell in The Analysis of Matter (Russell 1927).

For most of the twentieth century philosophers adopted a 'brain-first' approach to consciousness. The idea was that the brain is the thing we really understand, through neuroscience, and the task of the philosopher is to try to understand how that thing 'gives rise' to subjective experience: to the inner world of colours, smells and sounds that each of us knows in her or his own case. Russellian monists turn this on its head, arguing that physical science tells us surprisingly little about nature of the brain - and of matter more generally - and that it is the nature of consciousness that we really understand: through being conscious. The philosophical task, then, is to build our picture of the brain around our understanding of consciousness. In opposition to the brain-first approach, Russellian monists adopt a 'consciousnessfirst' approach to the mind-body problem.

In what sense does physical science tell us little about the nature of matter? In the public mind physics is on its way to giving us a complete account of the fundamental nature of space, time and matter. Upon reflection, however, it becomes apparent that physical science is exclusively concerned with what matter does. Neuroscience characterises brain states in terms of their causal role in the overall functional economy of the brain, and in terms of their chemical constituents. Chemistry characterises those chemical constituents in terms of their causal relationships and in terms of their physical constituents. And physics characterises basic physical properties entirely dispositionally. Mass, for example, is characterised in terms of the dispositions to attract and to resist acceleration. The physical sciences provide us with rich information about how physical entities behave but tell us nothing about their intrinsic nature.

One response to this fact is to deny that matter has an intrinsic nature, in so far as this is defined as something which would go beyond its causal properties. Let us say that a physical object — such as an electron or the cerebellum-has an intrinsic nature' just in case it instantiates categorical properties, where a 'categorical property' is defined as a property with a more-than-merely-dispositional nature, that is to say a nature that cannot be completely captured in causal terms. ${ }^{1}$ A categorical property may involve, or realise, causal powers, but there is more to its nature than its causal features.

Why believe in intrinsic natures and categorical properties? If physics just tells us what matter does, then maybe that's all there is to matter. Maybe once you know what an electron does, you know everything there is to know about what an electron is. On this view-known in the philosophical literature as 'dispositional

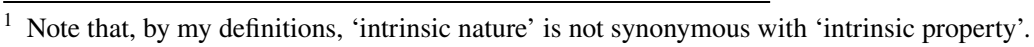


essentialism' - physical entities are not so much beings as doings (Bird 2007; Ellis 2001, 2002; Molnar 2003; Mumford 2004). If dispositional essentialism is intelligible, then the postulation of categorical properties seems to be surplus to requirements.

Russellian monists have argued that the universe described by dispositional essentialists is not intelligible, as its characterisation of physical properties inevitably ends up involving either vicious regress or vicious circularity; this is known as 'the regress argument' (Campbell 1976; Robinson 1982; Blackburn 1990; Armstrong 1997; Heil 2003; Lowe 2006; Goff 2017: Ch. 6). A disposition is defined in terms of its manifestation: the property which comes to be instantiated when the disposition is manifested. The manifestation of fragility, for example, is breaking. You can't understand the nature of a disposition until you know what its manifestation is; you don't know what fragility is, for example, until you know what it is for something to break. But according to dispositional essentialism, all properties are dispositions, and hence the manifestation of any given disposition A will itself be another disposition $\mathrm{B}$, and the manifestation of $\mathrm{B}$ will be another disposition $\mathrm{C}$, and so on ad infinitum. The nature of A cannot be understood until one understands B (as one cannot understand the nature of a disposition until one knows the nature of its manifestation), and one cannot understand the nature of $\mathrm{B}$ until one understands the nature of $\mathrm{C}$, and so on for ever. It is thus impossible for anyone to understand the nature of any of the properties instantiated in a dispositional essentialist universe. In other words, a dispositional essentialist universe is unintelligible.

If the regress argument is sound then there must be categorical properties underlying the dispositions ascribed by physical science. But even if it is not, it is surely coherent to suppose that physical properties involve categorical properties. ${ }^{2}$ The core of the Russellian monist proposal is simply that: (i) physical properties involve categorical properties, and (ii) consciousness is explained in terms of those categorical properties. ${ }^{3}$

The attraction of Russellian monism is that it promises to avoid both the problems facing dualism and the problems facing standard physicalism. The dualist claims that consciousness is a fundamental property distinct from the physical properties of the brain. But interactionist dualism is arguably incompatible with physical causal closure, the thesis that every physical event has a sufficient physical cause; and physical causal closure is something many take to have strong empirical support. ${ }^{4}$

\footnotetext{
${ }^{2}$ Some Russellian monists identify physical properties with categorical properties; on this view, mass is a categorical property picked out in physics in terms of causal role. Others hold that physical properties are dispositions that are grounded in categorical properties. I will use the world 'involve' to cover both of these options.

${ }^{3}$ In Goff (2017), I give a more detailed definition of Russellian monism to distinguish it from forms of physicalism which are also committed to categorical properties.

${ }^{4}$ Probably the best defence of this is Papineau (2001). I discuss the issue in some detail in Goff (2017): Ch 9.
} 
If the physical events involved in my writing this essay can be entirely explained in terms of physical events in my brain, then this would seem to 'crowd out' the possibility of my conscious thoughts having any role to play (assuming that the dualist is correct that my conscious thoughts are distinct from my physical brain processes). ${ }^{5}$ The physicalist avoids this problem by identifying conscious states with physical or functional states of the brain. ${ }^{6}$ The problem is that there are powerful argumentsthe knowledge argument and the conceivability argument-which seem to show that conscious states cannot possibly be identical with physical or functional states of the brain (Jackson 1982; Chalmers 2009; Goff 2017).

The Russellian monist avoids the problems facing dualism by identifying conscious states with categorical-property-involving states of the brain. In a sense, they accept physical causal closure, if the 'sufficient physical causes' in terms of which any given physical event can be explained can include categorical properties. The Russellian monist accepts that my typing of this essay can be entirely explained in terms of categorical-property-involving states of my brain, but this does not exclude my conscious thoughts playing a role, as (according to Russellian monism) my conscious thoughts exist among those categorical-property-involving states of my brain (Chalmers 2015; Goff 2017). ${ }^{7}$

Why is the Russellian monist identity between conscious states and physical states not ruled out by the knowledge and conceivability arguments? These arguments rule out the identification of conscious states with causal-structural properties revealed by physical science, but they do not have any bearing on the identification of conscious states with certain of the categorical properties that (according to Russellian monism) underlie those causal-structural properties. To take the conceivability argument, it is plausible that we can conceive of a creature that duplicates a human in terms of all of its causal-structural features but which nonetheless lacks consciousness; it is much less clear that we can conceive of a creature that duplicates a human being in terms of its categorical properties but which nonetheless lacks consciousness (Stoljar 2001; Chalmers 2015; Goff 2017).

\section{Varieties of Russellian monism}

\section{Panpsychist versus neutral forms of Russellian monism}

Russellian monists are united in believing that basic physical properties involve categorical properties and that those categorical properties are involved in the grounding of consciousness. But they disagree concerning the positive nature of the basic

\footnotetext{
5 I am assuming in this example that thoughts are a kind of conscious state. This is somewhat contentious, but a different example, using a less contentious example such as pain, could easily be given.

6 It is generally held that over-determination (there being two distinct sufficient causes for a single effect) is innocuous in cases in which one of the two causes is constituted by the other (Bennett 2003; Goff 2017: Ch. 6). Hence, given that functional states are constituted of physical states, the identification of conscious states with functional states does not lead to worrying over-determination.

7 Howell (2015) argues that Russellian monism cannot avoid causal exclusion worries.
} 
categorical features of the physical world. Panpsychist Russellian monists take the categorical properties involved in basic physical properties to themselves be consciousness-involving. Thus, the consciousness-involving properties of the macrolevel human brain are grounded in consciousness-involving properties at a more basic level (Strawson 2006; Goff 2017). Neutral Russellian monists, in contrast, deny that the categorical properties involved in basic physical properties are consciousness-involving. Some neutral Russellian monists offer a positive alternative account of their categorical nature, others accept that (at least at present) we have no clear idea of what their categorical nature amounts to. ${ }^{8}$

I have previously argued that once one accepts Russellian monism, there is a clear simplicity argument for panpsychist over neutral versions (Goff 2017). From the starting point that (i) physical science tells us nothing about the intrinsic nature of matter, and (ii) some material entities, i.e. brains, have a consciousness-involving intrinsic nature, the most simple and elegant supposition is that the intrinsic nature of entities outside of (and of the proper parts of) brains is continuous with that of brains in also being consciousness-involving. However, for the purposes of this paper, it is sufficient that panpsychist forms of Russellian monism are no less parsimonious or otherwise problematic than neutral versions. Assuming Russellian monism, basic matter must have some intrinsic nature that goes beyond the causal-structural properties revealed by science, and it is no less parsimonious to suppose that it has a consciousness-involving rather than a non-consciousness-involving intrinsic nature. ${ }^{9}$

\section{Smallism versus priority monism}

Philosophers tend to assume that big things are grounded in little things; that a table, for example, exists and is the way it is because of complex facts about its most fundamental constituents and their arrangements. Let us call this widespread view 'smallism.' ${ }^{10}$ However, there is an alternative: priority monism, the view according to which little things are grounded in big things and ultimately everything exists and is that way it is because of facts about the universe as a whole (Schaffer 2009, 2010). For the priority monist, the universe is the one fundamental entity.

Russellian monism comes in both smallist and priority monist forms. For the smallist, fundamental categorical properties are instantiated by micro-level physical entities, perhaps electrons and quarks. For the priority monist, the most fundamental categorical properties are instantiated by the universe as a whole. By cross-sectioning this distinction with the panpsychist/neutral distinction, we get four categories of Russellian monism:

\footnotetext{
${ }^{8}$ Coleman (2016) offers a positive proposal concerning the intrinsic nature of matter. Pereboom (2011) hopes that we will one day theorise our way to a positive proposal. McGinn (1989), I believe, can be interpreted as a holding a form of neutral Russellian monism according to which humans are constitutionally incapable of ever grasping the intrinsic nature of matter.

9 There are, for course, challenges for panpsychism, most notably the combination problem (Goff 2006, 2009, 2017; Coleman 2014; Chalmers 2016). I have argued (Goff 2017: Ch. 7) that these are no greater than the problems facing neutral Russellian monism.

10 This term is from Coleman 2006.
} 
- Smallist panpsychism: Fundamental categorical properties are instantiated by micro-level entities and are consciousness-involving.

- Priority monist panpsychism (AKA constitutive cosmopsychism): Fundamental categorical properties are instantiated by the universe as a whole and are consciousness-involving (Shani 2015; Nagasawa and Wager 2016; Goff 2017; Albahari forthcoming).

- Smallist neutral monism: Fundamental categorical properties are instantiated by micro-level entities and are not consciousness-involving.

- Priority monist neutral monism: Fundamental categorical properties are instantiated by the universe as a whole and are not consciousness-involving. ${ }^{11}$

Constitutive cosmopsychism is the form of Russellian monism which will be relevant for our purposes, as it is this view that I will argue can account for cosmic fine-tuning. I have in previous work defended constitutive cosmopsychism on independent grounds (Goff 2017). But I will assume here only that constitutive cosmopsychism is not obviously problematic or inferior to other forms of Russellian monism. ${ }^{12}$ If constitutive cosmopsychism can indeed offer us an explanation of cosmic fine-tuning, then this may in itself give us reason to prefer it.

\section{II - The fine-tuning problem}

There are a number of parameters in the basic laws of physics and initial conditions of the universe that are such that, for life to be possible, the values of those parameters needed to fall in an exceedingly narrow range. As a result, the physical possibility of life, given the kind of laws we have, turns out to be extremely improbable.

Here are three examples:

- The strong nuclear force (the force that binds together the elements in the nucleus of an atom) has a value of 0.007 . If that value had been 0.006 or less the universe would have contained nothing but hydrogen. If it had been 0.008 or higher the hydrogen would have fused to make heavier elements. In either case,

\footnotetext{
11 The first 'monism' in this name refers to token-monism (there is only one fundamental individual), the second to type-monism (there is only one fundamental type of individual). As far as I know, nobody defends priority monist neutral monism.

12 Whereas smallist panpsychism faces the combination problem, constitutive cosmopsychism faces the de-combination problem: the challenge of making sense of how human and animal consciousness is grounded in the consciousness of the universe. I have argued (2017: Ch. 9) that there are plausible solutions to this worry. Even if the combination/de-combination problems turn out to be insoluble, there is always the option of adopting emergentist forms of these views (Mørch 2014; Shani 2015), according to which human and animal consciousness causally arise from the consciousness of the cosmos and hence facts about human consciousness are not reducible to facts about the consciousness of the universe. The emergentist position may also be attractive if one wishes to accommodate libertarian free will. Some have argued that priority monism is at odds with contemporary science, e.g. Lowe 2012. However, Schaffer (2010) has argued that priority monism fits much better with the empirical phenomenon of quantum entanglement. Overall, it's fair to say that there are no obvious disadvantages to constitutive cosmopsychism relative to other forms of Russellian monism.
} 
any kind of chemical complexity would have been physically impossible. And without chemical complexity there can be no life (Rees 2008: Ch. 4).

- The physical possibility of chemical complexity is also dependent on the masses of the basic components of matter: electrons and quarks. If the mass of a down quark had been greater by a factor of 3 , the universe would have contained only hydrogen. If the mass of an electron had been greater by a factor of 2.5 , the universe would have containing only neutrons: no atoms at all, and certainly no chemical reactions. In fact, it's balanced on a knife edge: the mass-values compatible with chemical complexity fall within an extremely narrow range (Lewis and Barnes 2016: Ch. 2).

- Gravity seems a momentous force but it is actually much weaker than the other forces that affect atoms, by about $10^{36}$. This secures an important feature of our universe: astronomical processes have immense timespans relative to the basic microphysical timescales of physical and chemical reactions. If gravity had been only slightly stronger, relative to electromagnetism, stars would have formed from smaller amounts of material, and consequently would have been smaller with much shorter lives. A typical sun would have lasted around 10,000 years rather than 10 billion years, not allowing enough time for the evolutionary processes that produce complex life. Conversely, if gravity had been only slightly weaker (and/or electromagnetism slightly stronger), stars would have been much colder and hence would not have exploded into supernovae. This also would have rendered life impossible, as supernovae are the main source of many of the heavy elements that form the ingredients of life (Lewis and Barnes 2016: Ch. 2).

Some take the fine-tuning to be simply a basic fact about our universe: fortunate perhaps, but not something requiring explanation. But many scientists and philosophers find this implausible. Lee Smolin has estimated that, taking into account all of the fine-tuning, the chance of life being physically possible in a universe with laws/initial conditions of the general form we find in our universe is 1 in $10^{229}$, from which he concludes, 'In my opinion, a probability this tiny is not something we can let go unexplained. Luck will certainly not do here; we need some rational explanation of how something this unlikely turned out to be the case' (Smolin 1999: 45, quoted in Ratzsch and Koperski 2015). ${ }^{13}$

In what follows I will assume the very common, although not uncontroversial, view that the fine-tuning needs to be explained (we will reflect a little more in section IV on why it needs explaining). We are rationally obliged to give some account of why, seemingly against extraordinary odds, these parameters have precisely the values needed in order for life to be physically possible. ${ }^{14}$

\footnotetext{
13 There are some concerns with how to make sense of these probabilities. Attempts to address these concerns can be found in Collins 2009 and Hawthorne and Isaacs 2018. I intend to give my own account of the probabilities in question in future work.

14 In a recent unpublished paper, Hawthorne and Isaacs (2018) have argued that the fine-tuning argument is better expressed in terms of Bayesian probability theory. I agree that the deeper story of why the fine-tuning needs explaining should be put in Bayesian terms. However, I worry that setting things up this way will exclude everyone except techy academic philosophers from the discussion. For most purposes it seems to me fine to discuss the fine-tuning in the ideology of inference to the best explanation, so long as one appreciates that there is a deeper Bayesian analysis.
} 
The two standard explanations of the fine-tuning are: theism and the multiverse hypothesis. Theists postulate an all-powerful, all-knowing and perfectly good supernatural creator of the universe, and then explain the fine-tuning in terms of the good intentions of this creator. ${ }^{15}$ Life is something of great objective value; God in Her goodness wanted to bring about this great value, and hence created laws with parameters compatible with its physical possibility (Collins 2009; Hawthorne and Isaacs 2018). The multiverse hypothesis postulates an enormous, perhaps infinite, number of physical universe other than our own, in which many different values of the parameters are realised. Given a sufficient number of universes realising a sufficient range of the parameters, it is not so improbable that there will be at least one universe with fine-tuned laws. ${ }^{16}$

Neither of these views is attractive. The multiverse hypothesis comes at great ontological cost, in postulating an enormous number of concrete, unobservable universes distinct from our own. All things being equal, a more parsimonious explanation of fine-tuning would be preferable. It might be thought that theism is indeed more parsimonious, in postulating only one universe and one designer. However, whilst theism does not incur a large cost in terms of quantitative parsimony, it does incur a significant cost in terms qualitative parsimony.

Whereas quantitative parsimony is a matter of believing in as few token entities as possible, qualitative parsimony is a matter of believing in as few types of entity as possible. If the only difference between our theories of the world is that you believe that there are more electrons in the universe than I do, then our theories are equally matched as regards qualitative parsimony but mine is better as regards quantitative parsimony. On the other hand, if we agree about the number of particles in the universe but I believe they fall into 13 kinds and you believe they fall into 12 kinds, then our theories are equally matched as regards quantitative parsimony but yours is superior as regards qualitative parsimony. Qualitative parsimony is standardly taken to be a more important theoretical virtue than quantitative parsimony: a dualist who believes in few souls is more profligate than a materialist who believes in many bodies (although ideally both forms of excess should be avoided).

Theism incurs great qualitative cost in so far as it postulates an immaterial and necessary being in addition to the physical and contingent universe. ${ }^{17}$ It also commits to a radically dis-unified conception of reality, with the natural world entirely distinct from the supernatural God; and unity is itself an important theoretical virtue.

\footnotetext{
15 There are, of course, forms of theism that depart from this classical definition of theism, and some of them would avoid some of the criticisms I raise here against theism as standardly understood. Process theologians (Whitehead 1929; Hartshorne 1953), for example, deal with the problem of evil by denying that God is omnipotent.

16 Some examples of physicists who have taken the postulation of a multiverse to be a rational response to fine-tuning are Susskind 2005; Greene 2011; Tegmark 2014. Some philosophers who have argued for this are Smart 1989; Parfit 1998; Bradley 2009.

17 If we already take ourselves to be committed to mind-body dualism, then the parsimony concern with respect to theism is slightly weakened, as we are already committed to non-physical entities. However, the availability of Russellian monism significantly weakens the case for dualism.
} 
Even more significant than their profligacy is the fact that these theories make false predictions. For the theist, the false prediction arises from the problem of evil. If one were told that a given universe was created by an all-loving, all-knowing and all-powerful being, one would not expect that universe to contain enormous amounts of gratuitous suffering. One might not be surprised to find it contained intelligent life, but one would be surprised to learn that life had come about through the gruesome process of natural selection. Why would a loving God who could do absolutely anything choose to create life that way? Prima facie theism predicts a universe that is much better than our own and, because of this, the flaws of our Universe count strongly against the existence of God.

Turning to the multiverse hypothesis, the false prediction arises from the socalled Boltzmann brain problem, named after the 19th-century Austrian physicist Ludwig Boltzmann who first formulated this problem although in a different context. Assuming there is a multiverse, you would expect our Universe to be a fairly typical member of the universe ensemble, or at least a fairly typical member of the universes containing observers (since we couldn't find ourselves in a universe in which observers are impossible). However, Penrose (2004) has calculated that in the kind of multiverse most favoured by contemporary physicists-based on inflationary cosmology and string theory-for every observer who observes a smooth, orderly universe as big as ours, there are 10 to the power of $10^{123}$ who observe a smooth, orderly universe that is just 10 times smaller. And by far the most common kind of observer would be a 'Boltzmann's brain': a functioning brain that has by sheer fluke emerged from a disordered universe for a brief period of time. If Penrose is right, then the odds of an observer in the multiverse theory finding itself in a large, ordered universe are astronomically small. Many physicists take the fact that we find ourselves in such a universe to be a powerful disconfirmation of the multiverse theory.

Neither of these are knock-down arguments. Theists can try to come up with reasons why God would allow the suffering we find in the Universe, and multiverse theorists can try to fine-tune their theory such that our Universe is less unlikely. However, this can seem like special pleading or ad hoc alterations, desperate attempts to try to save the theory rather than accepting that, on its most natural interpretation, the theory is falsified. I think we can do better.

\section{III - Agentive cosmopsychism}

Constitutive cosmopsychism is a form of Russellian monism according to which (i) all facts are grounded in facts about the universe as a whole, (ii) the universe instantiates consciousness-involving categorical properties. Two modifications to the basic position are required if we want a view that can account for fine-tuning. In what follows I will outline these two modifications. 


\section{First modification: universe as agent}

According to constitutive comopsychism, the universe is a conscious subject. All other things - from planets to human beings to fundamental particles-are conscious subjects that exist as proper parts of the universe subject. ${ }^{18}$ We tend to think of wholes as 'built up' from parts. But for the constitutive cosmopsychist, it goes the other way around: facts about the proper parts of the universe are grounded in facts about the universe as a whole. The conscious universe is the ground of all being. It is certainly strange to think of one conscious subject being a proper part of another conscious subject, and it doesn't seem to be something we can positively imagine; but there is no contradiction or incoherence in the idea. Compare: we cannot imagine four-dimensional spacetime, but this gives us no reason to doubt the truth of general relativity. ${ }^{19}$

The claim that the universe is conscious does not imply that it has any of the sophisticated mental features enjoyed by human beings, such as thought, intelligence and agency. In our case, these mental phenomena are the result of millions of years of evolution; one might doubt that they could also be properties of things, such as the universe, which have not evolved through natural selection. Indeed, in previous work (Goff 2017), I suggested that the cosmopsychist conceive of the consciousness of the universe as being a 'mess' entirely lacking in elements of thought and rationality.

However, so long as we think of the causal capacities of the universe as entirely non-rational, it is unlikely that we will be able to explain fine-tuning. We could suppose that the universe has a disposition to develop laws with fine-tuned values. But if the universe is entirely non-rational, then the fact that it is disposed to develop laws with exactly those parameter-values required for life is going to remain an intolerable fluke.

Therefore, it seems likely that if the cosmopsychist wants to account for the finetuning, she must suppose not only that the universe is conscious, but that it is a conscious agent of some kind. By a 'conscious agent' I mean something with the capacity to recognise and respond to reasons or facts about value. Most human beings are agents in this sense. Although we are sometimes compelled to act by non-rational impulses, such as when driven by hunger or lust, most of the time we choose to do things because we think they are in some way worthwhile. In some cases, the motive may be the more lofty aim of making the world a better place. But even in mundane cases of choosing a restaurant, in general we recognise considerations that count in favour of the choice, e.g. that it would be pleasant and enjoyable. This is not to say that in general we act for the best reason, nor that our choices are not shaped by nonrational impulses. It is just to say that we are not creatures that are simply pushed

\footnotetext{
18 Strictly speaking, this is not quite correct. In the form of constitutive cosmopsychism I defend in Goff 2017 , some entities will admit of analysis, and we needn't think of those entities as themselves subject of experience. For example, we can analyse facts about parties into facts about people revelling, and consequently we don't need to postulate a subject of experience that is the party.

19 I defend the coherence of constitutive cosmopsychism in much more detail in Goff 2017: Ch. 9.
} 
and pulled by instinctive drives; we act to a large part on the basis of normative judgements about reasons. ${ }^{20}$

It is generally assumed that human agency is grounded in complex facts about our physical makeup, and I will not here question this assumption. However, we can conceive of possible creatures with a basic capacity to recognise and respond to reasons not grounded in anything more fundamental. This is, for example, the way we think about God or immaterial angels. It is also coherent to suppose that there are physical creatures with such a basic capacity; on certain emergentist views, the human capacity to recognise and respond to reasons is basic and ungrounded (O’Connor 2002).

The first modification I will be proposing is that the universe, although physical, acts, and only acts, through a basic capacity to recognise and respond to reasons. This is a strange proposal relative to how we ordinarily think about things. But it is arguably consistent with everything we can observe. It is commonly accepted that Hume was correct at least about the epistemology of causation. All that we can directly perceive in the world is the regular behaviour of physical things; we cannot directly observe the natural necessity that underlies those regularities: that which 'breathes fire into the equations', to use Stephen Hawking's memorable phrase (Hawking 1988). It could be, as is standardly assumed, that micro-level physical properties have their own causal powers, and that it is the operation of these causal powers that 'runs the show'. But it could also be that it is the decisions of the universe that run the show. ${ }^{21}$

Two objections may occur at this point, which it would be useful to consider together:

1. How do the laws of physics fit into this picture? If the universe acts through a basic capacity to recognise and respond to reasons, and all facts are grounded in facts about the universe, the laws of physics seem to be irrelevant to the causal evolution of the universe.

2. If the universe acts through recognising and responding to reasons, why do bad things happen, things which the universe would have presumably have overwhelming reason to prevent? This question invites a problem of evil analogous to that facing the theist.

Let me answer both of these questions at once by further clarifying the position. In contrast to the theist, the agentive cosmopsychist need not take the universe to be all-powerful. Rather she can take the laws of physics to record the limitations of the universe's capacity to act. On this interpretation, everything that happens is determined by the rational choices of the universe, but the universe can only do what is

\footnotetext{
${ }^{20} \mathrm{I}$ am working with the conception of human agency laid out in more detail in Scanlon 1998 and Dancy 2000.

21 Given that it offers an explanation of the fundamental regularities of the universe, in terms of the universe's responsiveness to value, agentive cosmopsychism is by definition opposed to Humean accounts of laws and causation. This is not an especially controversial commitment.
} 
physically possible, i.e. what is consistent with what the laws of physics state to be possible at any given time, given the properties of the universe at that time. ${ }^{22}$

This proposal might seem obscure and ad hoc. If the universe is the one fundamental entity and the sole arbiter of everything that happens, what could possibly restrict its ability to do what it wants? Proposing that the universe is shackled by 'the laws of physics' might seem to be an arbitrary way of avoiding the fact that the universe doesn't look like a place that has been shaped by a rational agent.

I would reply that this proposal is no more obscure or ad hoc than any other view about the fundamental causal workings of the universe. We know that the universe evolves according to certain laws. Why does this happen? Many philosophers postulate basic causal capacities defined such as to result in the universe we observe. ${ }^{23}$ The agentive cosmopsychist postulates a limited capacity to rationally act, defined such as to result in the universe we observe: the universe has a capacity to act for reasons but is limited in the options from which it can choose. Perhaps the influence of Western religion makes us prone to think of fundamental agents as having unlimited power, but there seems to be no incoherence in the idea of a fundamental agent with limited power. ${ }^{24}$

Of course, we should not adopt this view unless we have good grounds for doing so. But there is, I submit, a reason to take this proposal seriously: its capacity to explain the fine-tuning. Just as the theist explains the fine-tuning in terms of God's recognition and responsiveness to the fact that it would be good to have a universe containing life, so the agentive cosmopsychist can explain the fine-tuning in terms of the universe's recognition and responsiveness to this same normative fact. (We will explore agentive explanations of fine-tuning in more detail in section IV.)

More needs to be said. We can make sense of the idea that a creator who precedes the existence of the universe can shape its laws, by bringing into existence a universe with the laws it wants. But if the cosmic fine-tuner just is the universe, and hence presumably has existed only as long as the universe has, the question naturally arises: When was the fine-tuning done?

In fact, physics does not compel us to the idea that the fine-tuning existed from the first moments of the universe's existence. Our current models can tell us very little about the very first period of cosmological history: the so-called 'Planck epoch', lasting $10^{-43}$ of a second. The agentive cosmopsychist can propose that it was during this period that the universe chose fine-tuned values of the parameters and initial conditions (or rather, the conditions that obtained after the Planck epoch). The idea would be that in this early period of the universe, the universe had a constrained

\footnotetext{
22 Given that the universe is constrained by principles of conservation of energy, it cannot create or destroy matter, and hence can only act to alter itself.

23 Some take these causal capacities to be metaphysically basic (Bird 2007; Ellis 2001, 2002; Molnar 2003; Mumford 2004), but most Russellian monists take them to be grounded in categorical properties (Perebooom 2011; Chalmers 2015; Goff 2017).

24 As I explain below, I agree with Swinburne (2004) that considerations of simplicity favour an allpowerful fundamental agent; the point I am making here is about coherence. I explain below why overall I favour agentive cosmopsychism over theism.
} 
capacity to determine what its nature and its causal capacities would be after the Planck epoch:

- The laws that operated in the Planck epoch determined the form of the laws and initial conditions that would operate subsequently (the form we reach by taking the post-Planck epoch laws/initial conditions and abstracting away from the specific numerical values of their parameters) but did not determine the values of the parameters contained within them.

- The universe made it the case that the values of those parameters are compatible with the possibility of intelligent life, and it did this because intelligent life is of great value. $^{25}$

This may seem wildly speculative mystery-mongering, exploiting the limitations of our models to describe the first split second of the universe. But our best current science tells us that the universe emerged from the Planck epoch with fine-tuned laws and conditions. The only question is what is the best explanation of this. If the proposal of the agentive cosmopsychist-including the above hypothesis concerning what happened in the Planck epoch-is more parsimonious either than the postulation of a multiverse or of a supernatural God, then a case can be made for that proposal on the basis of its being the best explanation of the fine-tuning. More on this below.

The basic outline of the proposal should now be clear. But before we assess its theoretical virtue relative to the two standard explanations of fine-tuning, there is one more crucial modification required.

\section{2nd modification: representing the future}

I will argue in section $\mathrm{V}$ that the first modification comes at negligible ontological cost. However, this is sadly not true of the second modification. If, during the Plank epoch, the early universe fine-tuned the laws to bring about life billions of years in the future, then it must have in some sense known, or been aware, of the future consequences of its actions. In other words, to make sense of the idea that the early universe fine-tuned the laws and initial conditions in order to bring about life, we

\footnotetext{
25 The hardest bit of fine-tuning to fit into this model of explanation is the low entropy at the start of the universe. The level of entropy is determined by the arrangement of matter. Therefore, it's natural to suppose that if the universe intentionally determined what the level of entropy would be after the Planck epoch, she must have done this by determining the precise arrangement of matter. But if the universe had complete freedom to determine the arrangement of matter post-Planck epoch, then presumably she could have made reality much better than it actually is; thus, the problem of evil again raises its ugly head. It seems to me that we need to say that the universe had the power to determine the level of entropy but lacked the power to determine the precise arrangement of matter that would realise that level of entropy (thanks to Barry Loewer and Luke Barnes for help with this point). How is this possible? Perhaps the universe has the power to create a superposition of many different states of matter each of which has the same level of entropy, a superposition which subsequently collapses into one of those determinate states such that it is completely random which determinate state it will collapse into.
} 
need to make sense of the idea that the universe has mental states that represent the future.

I propose that the agentive cosmopsychist should suppose that the universe has a basic disposition to form spontaneous mental representations of the complete future consequences of all of the choices available to it. In a sense, this is a very simple postulation, in that the fundamental description of the disposition itself is simple. But I don't think it can be denied that the mental representations themselves, which result from the exercise of the disposition, add considerably to the cost of the theory. ${ }^{26}$

However, crucially, this cost is less than the cost incurred through the postulation of a multiverse. The proposed representational states of the universe involve great structural complexity, as will the postulation of a multiverse. However, there are important differences between the two proposals:

- On the multiverse hypothesis, the structural complexity is realised by an astronomical number of distinct individuals; on agentive cosmopsychism, the structural complexity is realised by the properties of a single individual.

- The multiverse hypothesis postulates an enormous number of individuals that we cannot directly observe; agentive cosmopsychism does not postulate a single new individual: it merely adds properties to an individual we already believe in, namely the physical universe. If we are already committed to constitutive cosmopsychism, this second modification merely adds to the complexity of the universe's consciousness.

I do not deny that this second modification, crucial for my proposal, comes at a cost. But it is less of a cost, I believe, than the multiverse hypothesis. This will be important in section $\mathrm{V}$, in which I ague that agentive cosmopsychism offers a better explanation of fine-tuning than its rivals.

\footnotetext{
${ }^{26}$ I don't think it would be implausible for the agentive cosmopsychist simply to take this disposition as basic, just as the theist takes the omniscience of God as basic. However, I also have some thoughts about a possible account of it in more basic terms. It could be that this disposition is grounded in the universe's having an acquaintance-based grasp of its causal power, i.e. of its limited capacity to recognise and respond to reasons. Grasping the nature of a causal power involves grasping the states of affairs that that causal capacity has the potential to produce. And hence, through grasping the nature of its causal power at time T1, the universe would grasp the possible states of affairs that it has the power to produce at T2. Presumably, each of those possible states of affairs that might exist at T2 would involves the universe's having a certain causal power at $\mathrm{T} 2$. Thus, the universe at $\mathrm{T} 1$, in grasping the possible states of affairs it has the power to produce at $\mathrm{T} 2$, would thereby grasp the nature of all of the possible causal powers it could have at T2 (which causal power it will have will presumably depend on which choice it makes); and if the universe at T1 grasps its causal power at T2, then it has-by the same line of reasoning employed above-a grasp of the potential states of affairs that at T2 it would have the power to bring about at T3. Its grasp of these potential states of affairs will afford it a grasp of the possible states off affairs that at $\mathrm{T} 3$ it will have the power to bring about at $\mathrm{T} 4$, and so on ad infinitum.
} 


\section{IV - Can fundamental agents explain the fine-tuning?}

In the next section, we will examine whether agentive cosmopsychism offers the best explanation of the fine-tuning. In this section, we will examine the prior question of whether it constitutes an explanation at all; more specifically, we will examine whether the postulation of fundamental agents - whether of the theistic or comopsychist variety - can explain the fine-tuning. I will begin by reflecting in a little more detail on the question of why we want an explanation of the fine-tuning in the first place.

In attempting to answer this question, most point to the extreme improbability of the fine-tuning. But whilst the fine-tuning is indeed extremely improbable, any combination of the parameter-values in question would be improbable; and, of course, each parameter had to have some value of other. Why then do we think that the fact that they turned out to have these values, rather than some other combination, needs explaining?

It is important to distinguish between something's being improbable, and something's being such that it's improbable that it happened by chance. ${ }^{27}$ Consider a random arrangement of pebbles on a beach. The fact that the pebbles happened to fall into that exact arrangement, of all the locations each might have had, is extremely improbable. But we don't think that this precise arrangement of pebbles requires explanation, as we don't find it improbable that it came about by chance. In order for some event to be not only improbable but also improbable that it happened by chance, it must be in some way marked out from all other possibilities. Suppose the pebbles clearly formed a complicated English word. Although this arrangement of pebbles is in a sense as improbable as any other arrangement, we would find it improbable that this happened by chance. We would seek an explanation, such as the hypothesis that someone had arranged them that way.

Returning to the topic at hand, suppose the strong nuclear force had turned out to have a value of 0.009 (rather than the fine-tuned value of 0.007 ). That would have been extremely improbable: Of all the values it could have had, it turned out to have exactly that value. But this fact would not have needed explaining. ${ }^{28}$ For there is nothing that marks out that value from other values, so as to incline us to think it improbable that the strong nuclear force had that value by chance.

The reason we think that the value of 0.007 needs explaining is, of course, that it is the value required for life. But pointing this out just pushes the lump to another part of the carpet, for we now need to ask what's so special about life. If the strong nuclear force had the value 0.009 , then presumably this would have made a difference; let us imagine that only in universes with a strong nuclear force of 0.009 are there precisely $10^{80}$ neutrons. We could then say that a value of 0.009 is 'fine-tuned'

\footnotetext{
27 In the discussion of this paragraph, I am largely following the approach and examples employed by White (2007) in a slightly different context.

${ }^{28}$ Of course, there would have been no one about to explain or not explain the value of the strong nuclear force in a universe in which its value is 0.009 . Nonetheless, I am assuming that whether or not a given phenomenon requires explanation is not determined by the preferences or actions of human beings.
} 
to allow a world with precisely $10^{80}$ neutrons, just as in our world the strong nuclear force is fine-tuned to allow a world with life. Still, it would not cry out for explanation if the strong nuclear force was 'fine-tuned' for this result, as there is nothing special about there being precisely $10^{80}$ neutrons.

The difference is that life, and ultimately intelligent life, is of great value. Without life, and especially without intelligent life, the universe would have had infinitely less value than it actually does; indeed, it is not implausible that it would have had no value. The fact that the strong nuclear force is precisely 0.007 is remarkable not simply because it is improbable (any number would have been equally improbable), but because it is precisely the number needed for allowing the universe to be a place of great value. More generally, of all the values the parameters of the laws/initial conditions might have had, they turned out to have exactly the values required to allow the universe to be a wonderful place. It is this that many cannot accept as a fluke. $^{29}$

The commitment to explaining fine-tuning, then, is dependent on a commitment to life/intelligent life being of great value. Moreover, the value in question must be of a fairly robust kind. Many philosophers hold that facts about value are dependent in some way on human preference or practices. But if the value of life is, in this way, in the eye of the beholder, then it is hard to see why the fine-tuning would need explaining. My existence is special to me in a way the existence of anyone else isn't (let's suppose). My existence is also extremely improbable; if any of my many great, great, great grandparents hadn't met, I would never have existed. And yet we don't think the fact that, against all the odds, I exist requires explanation, precisely because there's nothing objectively special about my existence as opposed to the existence of any other human being. Similarly, unless life/intelligent life is objectively of great value, the fine-tuning needs no explanation. ${ }^{30}$

\footnotetext{
${ }^{29}$ As I said in footnote 14, I agree with Hawthorne and Isaacs (2018) that the deeper story of why the fine-tuning needs explaining should be put in Bayesian terms but that I also think for most purposes I think it's fine to discuss the fine-tuning in terms of the ideology of inference to the best explanation. Moreover, I still think we need to commit to the objectivity of value when giving the Bayesian finetuning argument for design, in order to answer the worries about the motivations of the cosmic agent discussed in the rest of this section. If there is something objectively valuable about life, then fine-tuning is more likely conditional on the laws/initial conditions having been chosen by an agent than it is conditional on the laws/initial conditions having a non-agential cause or no cause at all. If there is nothing objectively valuable about life, then a cosmic agent may happen to like life but may equally happen to like random chaos; and therefore the probability of the fine-tuning conditional on the laws/initial conditions having an agential cause is no greater than the probability of the fine-tuning conditional on the laws/initial conditions having a non-agential cause. Something along these lines is, I think, the correct response to the challenge (considered by Hawthorne and Isaacs) to the proponent of the fine-tuning argument for God to explain why the fine-tuning does not support the existence of a God with a Tungsten fetish.

${ }^{30}$ The dependence of fine-tuning arguments on objective value is explored and defended in Mulgan 2015. The value subjectivist proponent of the fine-tuning argument might respond in the following way: What needs explaining is that the fact that the laws of nature mirror our preferences; we value life, and the laws of nature are, against all the odds, fine-tuned for life. However, it is inevitable (or at least highly likely) that evolved creatures will value life, and the existence of life is impossible without fine-tuned laws. And thus, we do not need an explanation as to why these two things- - the fine-tuning and the fact that humans value life-have met in the same universe.
} 
The fact that the commitment to explaining fine-tuning involves a commitment to objective value is important when responding to a certain form of objection to agentive explanations of fine-tuning (of course, the target is usually taken to be God, but the same form of objection would apply equally to natural agents). The objection I have in mind is that we have no grounds for making assumptions about how a divine or cosmic agent is likely to act. Elliot Sober puts it as follows:

Our judgements about what counts as a sign of intelligent design must be based on empirical information about what designers often do and what they rarely do. As of now, these judgements are based on our knowledge of human intelligence. The more our hypotheses of intelligent designers depart from the human case, the more in the dark we are as to what the ground rules are for inferring intelligent design (Sober 2003: 38).

This objection might a good one if we are thinking of motivation along Humean lines, i.e. that agents are ultimately motivated by basic desires, basic in the sense that the agent did not adopt those desires on rational grounds. But this is not the way I am thinking of the cosmic agent. The cosmic agent acts not from a pre-existing stock of brute desires, but because she recognises what she has reason to do. ${ }^{31}$ Given this non-Humean understanding of the cosmic agent's agency, we are in a position to predict her motivations: she is likely to be motivated to promote what is of value.

Richard Swinburne has argued that an agent who knows the normative truth, and who is not subject to non-rational influences, will inevitably perform the best possible action [if there is one (Swinburne 2004: Ch. 5)]. If she knows what she has overwhelming reason to do, and there are no desires pressing her in another direction, then why on earth wouldn't she do it? Perhaps Swinburne exaggerates, but it is certainly not surprising or unlikely that an agent with a capacity to recognise and respond to reasons should be motivated to do what she has reason to do. In so far as we think life is of great objective value, then it is likely that a (non-Humean) cosmic agent would be motivated to bring it about.

Or at least this is the case assuming that the cosmic agent's capacity to recognise and respond to reasons works well. What right do we have to suppose that? And what right do we have to suppose that the cosmic agent is not subject to irrational desires? These are all possibilities, but they are not all equally simple. Richard Swinburne points out that, in the absence of evidence to the contrary, scientific practice has exhibited a preference for the values of zero and infinite over values in between, on the basis of their greater simplicity:

...the hypothesis that some particle has zero mass, or infinite velocity, is much simpler than the hypothesis that it has a mass of 0.34127 of some unit, or a velocity of $301,000 \mathrm{~km} / \mathrm{sec}$. A finite limitation cries out for an explanation of why there is just that particular limit, in a way that limitlessness does not. And scientific practice shows this preference for infinite values over finite values of a property. It preferred to postulate that light had an infinite velocity rather

\footnotetext{
${ }^{31}$ Given that the cosmic agent is a person, it seems appropriate to refer to her with a personal pronoun.
} 
than a particular large finite velocity - for example, $301,000 \mathrm{~km} / \mathrm{sec}$. - until data found that were very improbable on the former hypothesis...And...[scientists]...have always preferred hypotheses that some particle had zero mass to hypotheses that it had some very small mass, when both were equally compatible with the data. There is a neatness about zero and infinite that particular finite numbers lack (Swinburne 2004: 55 and 97).

With reference to these kind of considerations, Swinburne argues that the postulation of an all-knowing and all-powerful divine being is much simpler than the postulation of a divine being with some arbitrary limit to its knowledge or power (Swinburne: 2004: Ch. 5). Along similar lines, I submit that the hypothesis that the universe has a flawless capacity to recognise and respond to reasons is much simpler than the hypothesis that this capacity of the universe has some arbitrary flaw; likewise, the hypothesis that the universe is not subject to irrational desires is simpler than the hypothesis that it is. ${ }^{32}$ In the absence of any reason to believe a more complex hypothesis, a simpler one is to be preferred.

Along similar lines, I am inclined to think that the postulation of an evil or irrational cosmic agent to explain the suffering and imperfections of the world is inferior to the postulation of a cosmic agent of limited power. In his 'evil God challenge', Stephen Law demands of the theist an explanation of why an evil God is less likely than a good God (Law 2010). One could argue that the good in the world allows us to rule out an evil God, but such a case would seem to mirror the familiar argument that the evil in the world rules out a good God. Whilst I agree that the problem of evil makes theism untenable, I do think a case can be made that an evil divine agent is less likely than a good one, at least if we have a non-Humean understanding of divine agency. On a Humean conception of the divine agent, God could have any desires whatsoever, and an evil God is just as likely as a good God. ${ }^{33}$ However, if the evil God is a non-Humean agent, then there must be some explanation of her evil motivations. Perhaps her capacity to recognise reasons is in some way flawed; perhaps she is subject to irrational desires; perhaps there is a mixture of the two. In any case, a theory that postulates an evil God must tell some such story, and moreover it must be one that predicts the universe as we find it. Such a theory is going to end up extremely complicated. My preferred story-that the cosmic agent has a flawless capacity to recognise and respond to reasons but has power-limitations expressed by the laws of physics—is much simpler.

\footnotetext{
32 My argument here is very much influenced by Swinburne 2004, but I disagree with him in two respects: (i) Although the ascription of omniscience is, in a sense, very simple, I agree with Richard Dawkins (2006: Ch 4) that the complex representational states of God entailed by Her omniscience constitute a significant cost to theism (similarly, my cosmic agent's awareness of the future involves significant cost), (ii) Although there is a simplicity-based consideration in favour of omnipotence, the existence of evil renders it more probable overall that the fundamental agent (if there is one) has limited power.

${ }^{33}$ I am setting aside for the sake of this discussion other arguments that might give us reason to think that God is perfectly good, such as the ontological argument.
} 
To emphasise, I am not assuming a non-Humean view of human agency, only of cosmic agency. ${ }^{34}$ I am assuming a commitment to objective value. But, as I have argued, one already has that commitment if one is committed to explaining fine-tuning.

With the non-Humean conception of the cosmic agent in place, the agentive cosmopsychist's explanation of the fine-tuning is straightforward. It is not left an intolerable fluke that, of all the values the parameters might have had, they turned out to have exactly the values required to make a universe of value; rather this fact is explained in terms of the rational responsiveness of a cosmic agent of limited power.

\section{V - Why agentive cosmopsychism offers the best explanation of the fine-tuning}

If the fine-tuning needs explaining, which I'm assuming it does, and there are multiple hypotheses that explain it, then we must try to assess without prejudice which is the best hypothesis. I will assume:

(i) that all three hypothesis we have considered-theism, the multiverse hypothesis and agentive cosmopsychism-explain the fine-tuning, in the sense of rendering it not an implausible fluke, ${ }^{35}$

and hence:

(ii) that we must decide which is the best explanation on the basis of (A) comparisons of theoretical virtue, such as parsimony (and simplicity more generally), elegance and unity, and (B) other advantages or disadvantages of each theory.

I will begin by assessing the relative theoretical virtue of the theories, before turning to other considerations.

Agentive cosmosychism is clearly more theoretically virtuous than theism. Both postulate a fundamental mind. But the fundamental mind postulated by theism is supernatural, immaterial and metaphysically necessary, leading to a disunified theory (God on the one hand, the natural universe on the other) and a significant cost in terms of qualitative parsimony (a commitment to both physical and non-physical kinds, and to both necessary and contingent kinds). Agentive cosmopsychism, in supposing that this fundamental agent is the intrinsic nature of the contingent, physical universe, avoids these costs.

How does agentive cosmopsychism fare in comparison to the multiverse hypothesis, as regards theoretical virtue? I have already argued that the second modification to turn constitutive cosmopsychism into agentive cosmopsychism incurs less cost than the multiverse hypothesis. But perhaps one might think that the first

\footnotetext{
34 In Goff 2018 I provide grounds for accepting a non-Humean account of human agency. This could provide further support for agentive cosmopsychism: if we already have a commitment to human nonHumean agency, then the postulation of non-Humean cosmic agency is not a wholly new commitment.

${ }^{35}$ I am assuming for the sake of discussion that the multiverse would explain the fine-tuning. In fact, there is reason to doubt this: see, for example, White 2000. I am currently working on a paper on the White argument.
} 
modification, or a basic commitment to Russellian monism itself, incurs more of a cost than a commitment to the multiverse hypothesis. Let us take these in turn.

I can see no grounds for thinking that constitutive cosmopsychism is more costly than any other form of Russellian monism. Priority monism is not more costly than smallism: if anything it's much cheaper, as there's only one fundamental thing! And a Russellian monist priority monist has to think there's some intrinsic nature to the cosmos. I can't see why the supposition that its intrinsic nature is consciousnessinvolving is any less costly than the supposition that it involves some non-consciousness-involving intrinsic nature (and if my simplicity argument for panpsychism goes through, it's less costly).

What about the move from cosmopsychism in which the universe is a nonrational 'mess' - call this 'standard cosmopsychism' - to cosmopsychism in which the universe is a rational agent (the first modification described above)? It is difficult to reflect on this question dispassionately, as we are strongly inclined for cultural reasons to think of the thesis that the universe is an agent as a ludicrously extravagant cartoon. But recall that agentive cosmopsychism is consistent with everything we can observe, and if we do manage to dispassionately assess its relative parsimony, it is not obvious that the transition to it-at least once one is already a Russellian monist-involves any cost at all.

After all, the (non-Humean) ${ }^{36}$ Russellian monist priority monist must make some postulation to account for the natural necessity that drives the universe; let us assume (reflecting the norm) that the standard cosmopsychist attributes to the universe multiple non-rational causal powers, in virtue of which the universe brings into being future states of itself in response to present states of itself. The agentive cosmopsychist instead postulates a limited capacity to recognise and respond to reasons. Which postulation is simpler? There are consideration of parsimony favouring each option:

- Considerations in favour of Standard Cosmopsychism-The causal capacity postulated by the agentive cosmopsychist is perhaps a little more complex than any single non-rational disposition, in that it involves a recognitional state (recognising that one has reason to $\varphi$ ) and a responsive state (responding to that reason by (ping).

- Considerations in favour of Agentive Cosmopsychism-The agentive cosmopsychist postulates only one causal capacity rather than multiple. ${ }^{37}$

\footnotetext{
36 As I explained in footnote 21, agentive cosmopsychism involves a commitment to non-Humeanism about causation. This is not an especially contentious theoretical preference.

37 On agentive cosmopsychism, the specification of the constraints of the universe's rational causal capacity-which express the complete laws of fundamental physics-will be more complex than the specification of any single causal power postulaedt by the standard cosmopsychist. But the complexity involved in specifying the fundamental power postulated by the agentive cosmopsychist will mirror the complexity of the causal powers postulated by the standard cosmopsychist taken as a whole (for those causal powers, as a whole, express the complete laws of physics). In this respect, the two hypotheses are equally complex. In saying that the agentive cosmopsychist 'postulates only one causal capacity' I was setting aside the second modification discussed in section III, which we have already (in section III) compared in cost to the multiverse hypothesis.
} 
In my judgment, the postulations of the agentive cosmopsychist are overall simpler. Perhaps some will disagree, but there is clearly not much in it. Even if the move from standard cosmopsychism to agentive cosmopsychism does involve a cost, that cost is negligible. When compared to other forms of Russellian monism, basic agentive cosmopsychism (i.e. cosmopsychism with the first modification) is not especially costly.

What of the cost simply of being a Russellian monist, or more specifically of postulating an intrinsic nature to physical reality, rather than just believing in the causal-structural properties postulated by physical science? If the regress argument against causal structuralism discussed earlier is sound, then we have no choice but to postulate an intrinsic nature to matter. Even if that argument isn't sound, the advantages of Russellian monism in terms of accounting for consciousness may make it worth postulating an intrinsic nature to physical reality. But suppose one rejects all independent reasons to postulate an intrinsic nature to matter (the regress argument and the knowledge/conceivability arguments that try to show that consciousness can't be explained in causal-structural terms) and is just looking for an explanation of the fine-tuning. Is it better to go for the multiverse hypothesis or agentive cosmopsychism? This is tough judgment call, but it seems to me overall better to add a little to the universe we have rather than to invest in an astronomical number of extra universes.

Moving on from considerations of theoretical virtue, the most significant advantage of agentive cosmopsychism is that it avoids the false predictions of its rivals. It is not subject to Penrose's Boltzmann brain problem, discussed above. And as regards the problem of evil, the agentive panpsychist is able to explain the imperfections of reality in terms of the limited powers of the universe. Indeed, she might plausibly claim that the universe made reality as good as possible given its limited powers.

Perhaps one could argue that there are certain possible values of the parameters of our physics that would have made the universe significantly better and press a problem evil against agentive cosmopsychism on this basis, but in the absence of such an argument it is not clear that agentive cosmopsychism faces any difficulty in this area. Even if such an argument could be pressed, it's possible that it could be countered by further qualifying the powers of the universe; we'd have to see the details. In any case, agentive cosmopsychism is in a significantly better position than theism with respect to the existence of evil and suffering.

Perhaps the theist may further support the existence of God with other arguments of natural theology, with the hope of showing that overall theism is to be preferred. I obviously do not have space here to consider all such possible strategies, and so will confine myself to making brief comments about the two other most discussed arguments for God: the ontological argument and the cosmological argument:

\section{The ontological argument}

If the ontological argument is sound, then the necessary existence of God can be demonstrated a priori, and hence the fine-tuning argument for God is redundant. 


\section{The cosmological argument}

Suppose the cosmological argument is able to demonstrate the existence of a timeless and necessarily existent cause of the big bang. In this case, the agentive cosmopsychist can accommodate this finding by adopting the following two theses:

- the entity E that is the physical universe exists necessarily and has its spatiotemporal properties contingently (i.e. 'physical universe' is a phase sortal of $\mathrm{E}$ as 'adulthood' is a phase sortal of a person),

- $\mathrm{E}$ as a non-spatiotemporal entity caused the big bang (i.e. the non-physical phase of E caused its physical phase). ${ }^{38}$

Given that physical science tells us nothing of the intrinsic nature of the universe, physical science can give us no grounds for holding that something with such an intrinsic nature is essentially spatiotemporal. In this way, the agentive cosmopsychist is able to avoid both the theistic problem of evil and a vicious dichotomy between God and the universe. In other words, one can accept the finding of the cosmological argument whilst still avoiding the profligate and problematic implications of theism. ${ }^{39}$ Of course, the cosmological argument may not demonstrate anything significant at all, in which case a contingentist form of agentive cosmopsychism will have even more of an advantage over theism in terms of parsimony. ${ }^{40}$

\section{VI - Conclusion}

I have argued not only that agentive cosmopsychism can explain the fine-tuning, but that it offers an explanation superior to its two main rivals: theism and the multiverse hypothesis. Those who accept the need to explain fine-tuning ought to take the view seriously. ${ }^{41}$

\footnotetext{
${ }^{38}$ Obviously we need to read 'phase' talk here in such a way that a phase can be non-temporal. If one is in doubt about the coherence of this, one can just stick to what is outside of the brackets.

${ }^{39}$ Craig (1991) argues that a timeless cause of the universe must be personal. I don't find these arguments persuasive, but in any case, the agentive cosmopsychist can accept their conclusions. There isn't, as far as I can see, anything in the cosmological argument that gives us grounds for believing that the cause of the universe is omnipotent or that that entity is presently supernatural.

${ }^{40}$ I lay out this position in more detail in Goff (forthcoming).

${ }^{41}$ This paper was written with support from a Summer Stipend from the Templeton project 'Pantheism and Panentheism'. I am grateful for comments from Yujin Nagasawa, Andrei Buckareff, Hedda Hassel Mørch, Barry Loewer, Luke Barnes, David Chalmers, Emma Bullock, Fana Schiefen, Godehard Brüntrup, Ludwig Jaskolla, Benedikt Göcke, two anonymous reviewers and participants at 'Idealism and the Mind-Body Problem', NYU Shanghai June 2017, 'Panpsychism and Panentheism', Catholic Academy of Schwerte February 2018, and at my presentation of this paper at the Ian Ramsey Centre, University of Oxford, March 2018, as part of the 'God, Good and Evil, in a Scientific Age' series. After publishing a popular version of this article, I was contacted by Justin Gaudry, who published a version of the same idea in a blog post in $2008 \mathrm{https}: / /$ panexperientialism.blogspot.com/2008/08/goldilocks-enigma.html (the term 'cosmopyschism' was also coined on Gaudry's blog).
} 
Funding Funding was provided by John Templeton Foundation.

Open Access This article is distributed under the terms of the Creative Commons Attribution 4.0 International License (http://creativecommons.org/licenses/by/4.0/), which permits unrestricted use, distribution, and reproduction in any medium, provided you give appropriate credit to the original author(s) and the source, provide a link to the Creative Commons license, and indicate if changes were made.

\section{References}

Albahari, M. (Forthcoming). Beyond cosmopsychism and the Great I Am: How the world might be grounded in universal 'Advaitic' consciousness. In W. E. Seager (Ed.), The Routledge handbook of panpsychism. London: Routledge.

Armstrong, D. M. (1997). A world of states of affairs. Cambridge: Cambridge University Press.

Bennett, K. (2003). Why the causal exclusion problem seem intractable, and how, just maybe, to tract it. Nous, 37(3), 471-497.

Bird, A. (2007). Nature's metaphysics: Laws and properties. Oxford: Oxford University Press.

Blackburn, S. (1990). Filling in space. Analysis, 50, 62-65.

Bradley, D. J. (2009). Multiple universes and observation selection effects. American Philosophical Quarterly, 46, 61-72.

Campbell, K. (1976). Metaphysics: An introduction. Encino, CA: Dickson.

Chalmers, D. (2016). The combination problem for panpsychsim. In G. Brüntrup \& L. Jaskolla (Eds.), Panpsychism: Contemporary perspectives. New York: Oxford University Press.

Chalmers, D. J. (2009). The two-dimensional argument against materialism. In B. McLaughlin (Ed.), The Oxford handbook of the philosophy of mind. Oxford: Oxford University Press.

Chalmers, D. J. (2015). Panpsychism and panprotopsychism. In T. Alter \& Y. Nagasawa (Eds.), Consciousness in the physical world: Essays on Russellian monism. Oxford: Oxford University Press.

Coleman, S. (2006). Being realistic: Why physicalism may entails panexperientialism. Journal of Consciousness Studies, 13(10-11), 40-42.

Coleman, S. (2014). The real combination problem: Panpsychism, microsubjects and emergence. Erkenntnis, 79(1), 19-44.

Coleman, S. (2016). Panpsychism and neutral monism: How to make up one's mind. In G. Brüntrup \& L. Jaskolla (Eds.), Panpsychism: Contemporary Perspectives. New York: Oxford University Press.

Collins, R. (2009). The teleological argument: An exploration of the fine-tuning of the cosmos. In W. L. Craig \& J. P. Moreland (Eds.), The Blackwell companion to natural theology. Oxford: Blackwell.

Craig, W. L. (1991). The existence of god and the beginning of the universe. Truth, 3, 85-96.

Dancy, J. (2000). Practical reality. Oxford: Oxford University Press.

Dawkins, R. (2006). The God delusion. New York: Random House.

Ellis, B. (2001). Scientific essentialism. Cambridge: Cambridge University Press.

Ellis, B. (2002). The philosophy of nature: A guide to the new essentialism. Montreal: McGill-Queen's University Press.

Goff, P. (2006). Experiences don't sum. Journal of Consciousness Studies, 13, 6.

Goff, P. (2009). Why pansychism doesn't help explain consciousness. Dialectica, 63, 3.

Goff, P. (2017). Consciousness and fundamental reality. Oxford: Oxford University Press.

Goff, P. (2018). Conscious thought and the cognitive fine-tuning problem. Philosophical Quarterly, 68(270), 98-122.

Goff, P. (Forthcoming). A self-explaining universe. In B. Göecke \& L. Jaskolla (Eds.), Panpsychism and panentheism. Notre Dame: Notre Dame University Press.

Greene, B. (2011). The hidden reality: Parallel universes and the deep laws of the cosmos. New York: Vintage.

Hartshorne, C. (1953). Reality as a social process. New York: Free Press.

Hawking, S. J. (1988). A brief history of time. New York: Bantam Books.

Hawthorne, J., \& Isaacs, Y. (2018). Fine-tuning fine-tuning. In M. A. Benton, J. Hawthorne, \& D. Rabinowitz (Eds.), Knowledge, belief, and god: New insights in religious epistemology. Oxford: Oxford University Press. 
Heil, J. (2003). From an ontological point of view. Oxford: Clarendon Press.

Howell, R. (2015). The Russellian monist's problems with mental causation. Philosophical Quarterly, 65(258), 22-39.

Jackson, F. (1982). Epiphenomenal qualia. Philosophical Quarterly, 32, 127-136.

Law, S. (2010). The evil God challenge. Religious Studies, 46(3), 353-373.

Lewis, G. F., \& Barnes, L. A. (2016). A fortunate Universe. Cambridge: Cambridge University Press.

Lowe, E. J. (2006). Personal agency: The metaphysics of mind and action. Oxford: Oxford University Press.

Lowe, E. J. (2012). Against monism. In P. Goff (Ed.), Spinoza on monism. Basingstoke: Palgrave Macmillan.

McGinn, C. (1989). Can we solve the mind-body problem? Mind, 98(391), 349-366.

Molnar, G. (2003). Powers: A study in metaphysics. Oxford: Oxford University Press.

Mørch, H. H. (2014). Panpsychism and causation: A new argument and a solution to the combination problem. Ph.D. thesis, University of Oslo.

Mulgan, T. (2015). Purpose in the universe: The moral and metaphysical case for ananthropocentric purposivism. Oxford: Oxford University Press.

Mumford, S. (2004). Laws in nature. London: Routledge.

Nagasawa, Y., \& Wager, K. (2016). Panpsychism and priority monism. In G. Br Brüntrop \& L. Jaskolla (Eds.), Panpsychism. Oxford: Oxford University Press.

O'Connor, T. (2002). Persons and causes: The metaphysics of free will. Oxford: Oxford University Press.

Papineau, D. (2001). The rise of physicalism. In C. Gillett \& B. M. Loewer (Eds.), Physicalism and its discontents. Cambridge: Cambridge University Press.

Parfit, D. (1998). Why anything? Why this? London Review of Books, 22, 24-27.

Penrose, R. (2004). The road to reality. New York: Vintage Books.

Pereboom, D. (2011). The prospects for physicalism. Oxford: Oxford University Press.

Ratzsch, D., \& Koperski, J. (2015). Teleological arguments for God's existence. In E. Zalta (Ed.), Stanford encyclopedia of philosophy. https://plato.stanford.edu/

Rees, M. (2008). Just six numbers: The deep forces that shape the universe. New York: Basic Books.

Robinson, H. (1982). Matter and sense. Cambridge: Cambridge University Press.

Russell, B. (1927). The analysis of matter. London: Kegan Paul.

Scanlon, T. (1998). What we owe to each other. Cambridge: Harvard University Press.

Schaffer, J. (2009). Spacetime: The one substance. Philosophical Quarterly, 145(1), 131-148.

Schaffer, J. (2010). Monism: The priority of the whole, Philosophical Review 123: 125-29, reprinted in Goff 2012. Spinoza on monism. Basingstoke: Palgrave Macmillan.

Shani, I. (2015). Cosmopsychism: A holistic approach to the metaphysics of experience. Philosophical Papers, 44(3), 389-437.

Smart, J. J. C. (1989). Our place in the universe: A metaphysical discussion. Oxford: Blackwell.

Smolin, L. (1999). The life of the cosmos. Oxford: Oxford University Press.

Sober, E. (2003). The design argument. In N. A. Manson (Ed.), God and design: The teleological argument and modern science (pp. 27-54). London: Routledge.

Stoljar, D. (2001). Two conceptions of the physical. Philosophy and Phenomoenological Research, 62, 253-281.

Strawson, G. (2006). Realistic materialism: Why physicalism entails panpsychism. Journal of Consciousness Studies, 13, 10-11.

Susskind, L. (2005). The cosmic landscape: String theory and the illusion of intelligent design. Columbus: Back Bay Books.

Swinburne, R. (2004). The existence of God (2nd ed.). Oxford: Oxford University Press.

Tegmark, M. (2014). Our mathematical universe: My quest for the ultimate nature of reality. New York: Knopf.

White, Roger. (2000). Fine-tuning and multiple universes. Nô̂s, 34(2), 260-267.

White, R. (2007). Does origins of life research rest on a mistake? Nous, 41, 3.

Whitehead, A. N. (1929). Process and reality: An essay in cosmology, Gifford lectures, 1927-1928. Basingstoke: Macmillan. 